\title{
0 papel de editores de revistas de associações científicas
}

Após uma jornada de quatro anos à frente da editoria da revista da Associação Brasileira de Estudos Populacionais, mas tendo seguido de perto seu caminho desde sua recuperação sob a editoria de Elizabete Dória Bilac, que enfrentou os desafios iniciais que possibilitariam sua entrada no Sistema SciELO sob a batuta de Carlos Eugênio Ferreira, é necessária uma breve reflexão sobre o que significa ser responsável pela edição de um periódico de associação.

Muito provavelmente os editores-chefes de revistas profissionalizadas, alguns deles até com recompensas monetárias e uma equipe especializada no apoio, têm problemas a resolver e também muito trabalho, no entanto, para um editor de revistas de associações científicas não profissionalizadas, o volume de trabalho e os desafios enfrentados são elevados à n-ésima potência. São exigidas habilidades administrativas e gerenciais, muita determinação para buscar recursos financeiros e, principalmente, muita paciência para fazer prestação de contas, além do básico, que compreende a experiência e as aptidões científicas no escopo de atuação da revista. No início do trabalho tive algumas dúvidas se teria capacidade para desempenhar bem este papel. Hoje não tenho dúvidas, mas sim a certeza de que ainda faltavam muito conhecimento e prática para exercer a tarefa da melhor maneira possível (certeza por experiência e não aquela que tinha quando ainda era muito jovem e pensava saber todas as respostas).

Parte do conhecimento adquirido ao longo desses anos foi obtida junto à Associação Brasileira de Editores Científicos (Abec), da qual a Rebep fazia parte desde 2003, mas o contato tinha sido perdido ao longo dos anos nas trocas de editores. A Abec, além de colaborar com instrumentos para o gerenciamento das revistas, como o acesso facilitado ao CrossRef (com a designação de DOls e com os detectores de plágio do CrossCheck), como diz Yamamoto, ${ }^{1}$ trabalha "expondo os periódicos, criando listas de discussão, enfim, multiplicando oportunidades de troca de experiências, buscando romper o isolamento que nos [os editores] caracterizava". No editorial da revista Estudos de Psicologia, este autor faz um excelente apanhado sobre o que os autores da área de Ciências da Informação consideram como responsabilidades de um editor, concluindo que não existe muita dúvida sobre quais são tais incumbências, ${ }^{2}$ mas sim a respeito das dificuldades para colocá-las em prática, principalmente em um mundo digitalizado e em áreas de pesquisa em que

\footnotetext{
${ }^{1}$ YAMAMOTO, O. H. As responsabilidades do editor de um periódico científico. Estudos de Psicologia, Natal, v. 7, n. 1, p. 3 , jan. 2002. Disponivel em: 〈http://dx.doi.org/10.1590/S1413-294X2002000100001〉. Acesso em: 26 dez. 2016.

${ }^{2}$ Yamamoto (op. cit., p. 4) resume estas responsabilidades como sendo: “(a) a responsabilidade de tomar decisões sobre os manuscritos com base em critérios objetivos e científicos, com presteza; (b) a proteção aos direitos dos autores e avaliadores; (c) a isenção na seleção dos consultores; (d) a responsabilidade pelo sigilo dos originais e imparcialidade no processo de avaliação; (e) a responsabilidade final, de forma judiciosa, pelo que é publicado na revista".
} 
praticamente todos se conhecem. Ainda vale citar outra passagem deste autor/editor, que diz muito sobre o perfil dos editores, ao mencionar que, comumente, "são pesquisadores que passam a se envolver na atividade de editoração como uma atividade paralela, muitas vezes, por circunstâncias fortuitas, sem reunir, de início, as condições/conhecimentos que seriam desejáveis para assumir tal responsabilidade". ${ }^{3}$

Nas revistas de associações, a troca periódica de editores cria desafios adicionais. Em geral, a cada mudança de diretoria, esta tem a prerrogativa estatutária de escolher o editor e, muitas vezes, até o Comitê Editorial que trabalhará com ele. Uma indicação fortuita de um editor que não seja especialista da área, ou que tenha pouca experiência, ou pouca capacidade de trabalho no ritmo exigido, e, ainda, a falta de liberdade na gerência da revista podem ser fatais para o avanço continuado desta. Apesar de o regimento da Rebep dar esta prerrogativa de escolha à diretoria, devo registrar que as gestões de 2013-14 e 2015-2016, principalmente do presidente Cássio Turra, me deram a valiosa liberdade incondicional de gerenciar a revista, permitindo a escolha do Comitê Editorial livremente e fornecendo o apoio financeiro necessário para completar os recursos do CNPq, para implementar as inovações que eram necessárias à Rebep. Somente posso agradecer imensamente todo esse apoio, confiança e liberdade que me foram dados e registrar que esta experiência e aprendizado foram valiosíssimos.

A escolha de tal assunto para ser tratado neste editorial não é por acaso. Na última reunião anual dos periódicos do SciELO, o papel e os desafios dos editores não profissionais foram um dos assuntos mais discutidos. No informe já publicado, Paker 4 relatou: "Tanto nas falas dos editores do painel como nas do público, ressaltou-se a necessidade de que políticas e autoridades valorizem adequadamente os periódicos do Brasil com projetos de apoio a médio e longo prazo e o estabelecimento de algum sistema que prestigie a função dos editores na carreira dos pesquisadores." A nova editora indicada pela diretoria 2017 18 , nossa colega demógrafa Simone Wajnman, a quem dou as boas-vindas e todo o apoio necessário para a continuidade dos trabalhos da Rebep, testemunhou esta reunião como sua primeira pré-atividade nessa função.

Os desafios para o próximo Comitê Editorial da Rebep são enormes, pois o mundo das publicações científicas vem mudando e a cobrança por mais e ainda melhores indicadores é fomentada pela ânsia daqueles que querem responder ao produtivismo científico, sem muita crítica e com soluções prontas ou iniciativas que geram efeitos não desejados, como, por exemplo, a tão conhecida prática dos periódicos predatórios. Além disso, existe uma inovação a mais que vem sendo discutida e que a SciELO pretende começar a implementar a partir de 2018, que são os chamados preprints, usados para imprimir velocidade à divulgação dos resultados de pesquisas. As idiossincrasias de cada área do conhecimento e os cuidados éticos que garantem a existência de um bom artigo científico precisam ser

\footnotetext{
${ }^{3}$ YAMAMOTO, O. H. (op. cit., p. 3).

${ }^{4}$ PACKER, A. SciELO e o futuro dos periódicos. SciElO em Perspectiva. 2016. Disponível em: 〈http://blog.scielo.org/ blog/2016/12/21/scielo-e-o-futuro-dos-periodicos/>. Acesso em: 25 dez. 2016.
} 
bem discutidos e pensados nesta inovação. Talvez uma boa leitura do Manifesto de Leiden sobre Métricas de Pesquisa fosse essencial para todos os editores, avaliadores, autores e aqueles envolvidos nesta proposta de inovação. ${ }^{5}$

Esta reflexão apontando as dificuldades encontradas, que espero sejam mais amenas para a próxima editora e seu Comitê Editorial, precisa conter a parte prazerosa de tal atividade. A experiência me conduziu à certeza de que o papel de um editor científico está entre as atividades mais nobres da pesquisa, pois, tarefas administrativas à parte, a atividade científica envolvida no relato dos resultados de pesquisa e as trocas com autores e avaliadores dos trabalhos permitem um aprendizado imensurável. 0 contato com os novos pesquisadores, ${ }^{6}$ ou aqueles que ainda têm pouca experiência em publicações em periódicos, é uma extensão da atividade docente, mas diretamente vinculada à prática da pesquisa. Assim, agradeço a todos os autores e avaliadores que me propiciaram esta vivência ímpar e espero que entendam algumas decisões tomadas.

Outra experiência seminal foi aquela estabelecida com os membros do Comitê Editorial. A valiosa colaboração e sabedoria desse grupo, que esteve na Rebep nos últimos quatro anos ou em parte deles, são enormemente reconhecidas em suas contribuições coletivas e, principalmente, na ajuda individualizada na tomada de decisão sobre submissões em situação de conflito, surgidas ao longo desses anos. Além de agradecer pelo trabalho, agradeço pela paciência com o idioma em um grupo multilíngue.

Finalmente, todas as inovações e, ainda, a manutenção da qualidade do trabalho de revisão e diagramação, já característica da Rebep, não seriam possíveis sem o profissionalismo e competência de nossas parceiras Vania Fontanesi, a equipe da Traço Publicações e Design (Fabiana Grassano e Flávia Fábio) e, juntando-se à equipe e somando na qualidade do trabalho, a assistente editorial Ana Paula Pyló, que acumulou sua função com a da secretaria da Abep. Este time, mesmo trabalhando à distância, se esmerou e foi fundamental para o sucesso da revista. As agradeço muitíssimo e espero que a Rebep possa continuar contando com sua colaboração. Antes de encerrar, passo a relatar a edição atual.

\section{Contribuições desta edição}

No final dos anos 1950, e na década seguinte, a demografia teve avanços metodológicos enormes que permitiram estimar as componentes demográficas em países com dados limitados e defeituosos, principalmente com os métodos e técnicas propostos por William Brass. Ele soube como ninguém tirar dos dados básicos, com erros de cobertura e de medição, alguns indicadores que davam uma boa noção da dinâmica demográfica nos países em desenvolvimento. A América Latina se beneficiou desses métodos e continua

\footnotetext{
${ }^{5}$ Disponível no idioma de sua escolha em: 〈http://www.leidenmanifesto.org/translations.html〉.

${ }^{6}$ Estes se beneficiariam com uma boa leitura de um texto publicado pela Abec intitulado "Recomendações para jovens pesquisadores", disponível em: 〈http://www.abecbrasil.org.br/arquivos/recomendacoes_publicacao_jovens_ pesquisadores.pdf`.
} 
utilizando-os paradoxalmente até os dias atuais. O Brasil não é exceção a essa regra, apesar da falsa sensação de muitos de que o país é exemplar na coleta de dados e análise de sua dinâmica demográfica. A realidade é que o Brasil tem uma infinidade de bases de dados, que, entretanto, ainda padecem de problemas de qualidade desses dados, principalmente devido à subnotificação dos registros vitais, continuando, assim, a serem empregados os métodos indiretos, que a demografia dos países desenvolvidos tirou de seus currículos há décadas, e alguns países nunca os incluíram. Muito menos, ainda não se avançou para possibilitar a identificação única nos registros de nascimentos e óbitos, sendo que as primeiras tentativas levaram à proposição impensada de um número com mais de 30 dígitos no registro de nascimento.

Adicionalmente, no caso do Brasil e de alguns outros países da região, tem-se o contrassenso de existirem dois sistemas de registro de eventos vitais que brindam estimativas distintas, cada um com seus erros decorrentes de suas especificidades, que implicam gastos públicos duplicados e ineficiência na capacitação de recursos humanos. Para os leitores não familiarizados com a demografia terem uma noção dos desafios que isso causa para os demógrafos, e para a sociedade em geral, e ainda para não entrar em detalhes, basta citar um único exemplo das dificuldades decorrentes deste problema quando se tenta responder qual é o tamanho da população brasileira (população total, nem se pensar nas populações por estados e muito menos por municípios). Pode-se afirmar, sem nenhum receio de errar, que ninguém conhece o tamanho exato da população brasileira, muito menos sua estrutura etária correta, e talvez o pior, apesar de haver várias estimativas, ninguém sabe, ou tem boas estimativas do erro associado a essas. A razão é muito simples: para saber quantos somos, é preciso saber quantos nascem, quantos morrem, quantos vão viver em outros países e quantos de outros países vêm viver aqui. Os dois primeiros eventos dependem dos registros vitais e o segundo de dados de migração capazes de medir a migração documentada e a indocumentada.

$\mathrm{Na}$ falta de bons registros vitais, os censos populacionais, que contam o número de domicílios no país e seus residentes, são há séculos a solução para informar sobre o número de habitantes, sua idade e sexo e outros recortes importantes. No entanto, enganam-se novamente aqueles que pensam que isso resolve o problema, pelo menos a cada cinco ou dez anos, pois o censo populacional ou contagem têm problemas de cobertura, assim como os registros vitais, ou seja, nos anos censitários não se "contam" $100 \%$ da população brasileira. Sem muita surpresa também, não se dispõe de boas estimativas do erro de cobertura dos censos. E como estimar a cobertura? Ou se faz por boas pesquisas de avaliação censitária (PA), como conhecidas no Brasil (ou desconhecidas, pois raramente os dados e metadados são de uso público), ou, surpresa, utilizam-se as projeções populacionais anuais, que já foram calculadas com erros, por falta de boas estimativas dos eventos vitais, fechando assim um ciclo de incertezas.

Estes problemas de qualidade dos dados demográficos continuam, desde os primórdios do século passado, sendo um desafio para os demógrafos de países em desenvolvimento. 
Se isso, por um lado, implica a busca por novos métodos para melhorar a precisão das estimativas provenientes de dados defeituosos, por outro, causa uma consequência indesejada, que é ter várias estimativas populacionais anuais por sexo e idade, dependendo de quem e com que métodos de correção as calcula. Por exemplo, quantas são as crianças em idade de vacinação ou quantas estão em idade escolar? E, principalmente, quantas ficaram sem vacinas e quantas estão fora da escola em determinado ano? Cada órgão responsável por esses serviços terá problemas e o que um bom demógrafo pode fazer para ajudar é tentar errar o menos possível em suas estimativas, pois a única certeza que terá é de que a estimativa estará sujeita a erro, maior ou menor dependendo da habilidade e da percepção do demógrafo e, às vezes, até da sorte.

Como não se quer, e não se deve, contar com a sorte, esta edição da Rebep traz vários artigos que lidam de uma forma ou de outra com estes problemas, na tentativa de buscar melhores indicadores para informar políticas públicas que melhoram a vida das pessoas. São também apresentados estudos com análises econômicas e sociais com foco na população, que são temas que avançaram metodologicamente bastante na região.

0 primeiro artigo, de Wanda Cabella e Ignacio Pardo, faz uma reflexão sobre as estimativas de fecundidade, componente que mais afeta o volume e composição etária da população da maioria dos países latino-americanos. A análise mostra uma face ainda mais paradoxal da demografia decorrente da avançada fase da transição demográfica da região, com taxas de fecundidade já baixas, mas com padrão etário tão diferenciado dos países desenvolvidos. Os autores se perguntam se os velhos indicadores de período não trarão maiores desafios às análises das tendências futuras da fecundidade por mudanças ocorridas no comportamento reprodutivo, devido à intensidade da fecundidade (efeito quantum) e ao calendário, ou à idade das mulheres no nascimento dos filhos (efeito tempo), e, assim, se estimativas mais refinadas da fecundidade na região deveriam ser usadas.

0 artigo de Sergio Almeida, Paula Pereda e Rafael Ferreira, que são de formação nas ciências econômicas, traz à tona um tema que o Brasil ainda conhece pouquíssimo por falta de dados, que é a participação masculina na reprodução. Para estimar os custos da ampliação da licença-paternidade, os autores fazem vários supostos para estimar a probabilidade de ser pai e a de pedir a licença-paternidade ampliada em um determinado ano, para então calcular os custos diretos desta política pública. Apesar desses vários supostos e de usar dados da PNAD, que dependem das projeções populacionais, por sorte ou não, o número de nascimentos anuais estimado é muito próximo ao registrado em um dos sistemas de eventos vitais. Com isso, os autores conseguem afirmar que o custo da ampliação da licença-paternidade no Brasil é muito baixo, mas resta agora analisar os benefícios, visto que uma política pública somente se sustenta se tiver uma boa relação custo-benefício, sejam estes financeiros ou não.

Por falar em política pública, o artigo de Luana Passos e Fábio Waltenberg apresenta uma análise daquela mais conhecida nos últimos anos no país, o Programa Bolsa Família. Os autores discutem o possível impacto que o programa teria na individualização das 
mulheres pobres, utilizando o método mais comumente aplicado em anos recentes para a análise de resultados em dados transversais, o qual, por ajuste probabilístico, encontra os "melhores" pares para comparação entre beneficiários e não beneficiários do programa. Reconhecendo os limites do método e do não tratamento do desenho amostral da pesquisa, e ainda empregando dados de 2006, que, além de desatualizados - os mais recentes disponíveis para esta análise -, referem-se a no máximo três anos de exposição ao programa, os autores concluem que o programa não contribuiu para mitigar os papéis tradicionais de gênero existentes no país, apesar de colocar a mulher como prioridade de recebimento do benefício.

A palavra paradoxo talvez seja uma das mais utilizadas neste editorial e é ela que novamente aparece no artigo de Pedro Henrique de Castro Simões, José Eustáquio Diniz Alves e Pedro Luis do Nascimento Silva. Os autores fazem uma análise detalhada do paradoxo do baixo desemprego no país, com uma série de 15 anos de dados, e mostram que aqueles que mais se beneficiaram com a queda do desemprego foram os que agora mais perdem com a crise atual, ou seja, os jovens, os menos instruídos e as mulheres, inclusive as que possuem curso superior. Segundo os autores, isso antecipa o fim do aproveitamento do bônus demográfico no mercado de trabalho, colocando para o país desafios ainda maiores para superar os problemas sociais e econômicos nas próximas décadas. Estes resultados, nas palavras dos autores, trazem “temores de que esta possa ser uma 'geração perdida”".

O próximo artigo nos dá a dimensão de uma das consequências que podem ocorrer com esta geração jovem, que, quando não encontra a devida inserção no mercado laboral, busca em países mais prósperos uma saída para seus projetos de vida. Os autores Leonardo Gomes de Sousa e Dimitri Fazito mostram evidências do continuado fluxo de emigrantes da região de Governador Valadares em direção aos Estados Unidos, mesmo diante de fatos ocorridos nos últimos anos, que levariam à suposição de que este deveria diminuir ou até cessar, ou seja, o maior controle das fronteiras com fiscalização da imigração não documentada e a crise econômica no país de destino em 2009. 0 artigo testemunha a dificuldade de obtenção de boas estimativas de saldos migratórios internacionais com a identificação da composição dos fluxos e se ampara na análise teórica e de redes de apoio para decifrar este evento, que poderá ter cada vez mais relevância na dinâmica demográfica. Ainda, os autores nos levam a compreender a formação dos sistemas migratórios da região.

Outro desafio a ser conhecido, compreendido e mitigado, decorrente da transição demográfica, é o envelhecimento populacional. Os dois artigos seguintes tratam deste tema a partir do ponto de vista da saúde. O primeiro deles, de Cristiano Sathler dos Reis, Kenya Noronha e Simone Wajnman, apresenta uma estimativa dos custos em saúde pública, teoricamente de acesso universal no país, mais especificamente sobre gastos com internações hospitalares, no contexto de envelhecimento populacional, que ocorre em velocidade intensa no país. Por meio da decomposição dos gastos em efeitos preço, taxa, composição etária e tamanho populacional e com desagregação por sexo e tipo de enfermidades, os 
autores mostram que o efeito composição etária é muito alto, principalmente nas enfermidades que são as mais prevalentes em idades mais avançadas, como as doenças do aparelho circulatório e neoplasias, e que existem importantes diferenciais por sexo.

0 segundo artigo sobre as consequências do envelhecimento populacional na saúde, assim como da maior longevidade da população, é apresentado por Angela Segura Cardona e colegas. Com a coleta de dados primários em uma região da Colômbia, as autoras analisam o risco de comprometimento cognitivo em idosos e sua associação com fatores sociodemográficos e regionais. Apesar de referente a um local específico, o estudo mostra como esta situação está relacionada com condições de vida de baixa qualidade, fato comum na maioria dos países da América Latina. Com o aumento dos gastos em saúde devido ao envelhecimento populacional, é essencial que políticas públicas de prevenção possam mitigar o aparecimento de comprometimento cognitivo em idosos, ainda mais diante de famílias cada vez menores e com maiores limitações para dividir com o Estado os custos do envelhecimento não saudável.

0 último evento no curso de vida, a mortalidade, é tratado em dois artigos. 0 primeiro deles, de Marcos Roberto Gonzaga e Carl Paul Schmertmann, apresenta um avanço metodológico na mensuração das taxas de mortalidade por idade e sexo em pequenas áreas. Os dados básicos para o cálculo dessa taxa estão sujeitos a dois problemas: aquele mencionado anteriormente sobre cobertura do registro de óbitos; e a variabilidade de pequenos números, devido a eventos raros. Este último é tratado pelos autores, para substituir o método de padronização comumente empregado no Brasil, que assume uma estrutura etária rígida da mortalidade. Os autores propõem utilizar um método que suaviza os dados sem impor um padrão etário preestabelecido, que mostra excelentes resultados. 0 problema de sub-registro dos óbitos em pequenas áreas, como indicado pelos autores, ainda precisa de avanços. Vale mencionar que este artigo traz uma inovação, utilizada por alguns estudiosos em periódicos internacionais, que merece ser seguida: a apresentação em endereço Web de todos os dados básicos, programas/sintaxes e resultados obtidos, disponibilizados de forma aberta a todos os interessados.

O segundo artigo sobre mortalidade, elaborado por Mário Moreira Carvalho de Oliveira e colegas, apresenta um importante avanço na estimação de tábuas de mortalidade para a população segurada com dados do mercado segurador brasileiro. Estas são essenciais para melhor determinação dos custos e prêmios dos seguros contratados por morte ou por sobrevivência. 0 artigo apresenta um volume grande de gráficos e tabelas, além daquele utilizado como padrão da revista, mas esta exceção é por uma boa causa, visto que este estudo servirá como referência para a demografia dos negócios, área importante e pouco explorada na demografia brasileira. Ao compararem os resultados com outras tábuas de vida, os autores mostram as desigualdades brasileiras no enfrentamento da adversidade, uma vez que somente ao redor de $22 \%$ da população, sendo a mais abastada, possui condições de contratar seguros. Este fato mostra o desafio das políticas públicas na área de saúde diante do envelhecimento populacional. 
0 último artigo desta edição oferece uma análise totalmente inovadora e valorosa, do ponto de vista dos usuários de dados, e corajosa mas essencial desde a perspectiva dos produtores de dados. Luciano Tavares Duarte, Denise Britz do Nascimento Silva e José André de Moura Brito analisam as informações produzidas no processo de coleta dos dados do Censo Demográfico de 2010, os chamados paradados. Os autores apresentam uma análise sobre as divergências entre as respostas coletadas pelos entrevistadores e aquelas obtidas na checagem pelos supervisores, comparando-as com as informações sociodemográficas desses e dos informantes do censo, sendo que umas das conclusões é que as características do informante são essenciais para uma boa coleta dos dados. 0 artigo deveria servir de base para novos avanços nesta área na América Latina, que, apesar da tradição na realização dos censos de população, tem pouca ou quase nenhuma prática no registro dos procedimentos adotados e, menos ainda, na avaliação da qualidade das informações coletadas, ou pelo menos na divulgação dessas. Apesar de ainda ser possível realizar outras análises, os resultados mostram importantes avanços para correções de rumo nos procedimentos censitários, no sentido de potencializar a melhoria da qualidade das informações coletadas em pesquisas domiciliares.

A edição também traz uma resenha do livro The color of love: racial features, stigma \& socialization in black Brazilian families, de Elizabeth Hordge-Freeman, que é apresentada por Maria Carolina Tomás.

Espera-se que estes artigos possam estimular o avanço metodológico e analítico da área, que vem crescendo ao longo dos anos, mas ainda tem importantes caminhos a percorrer.

Boa leitura! 